\title{
Are Cardiometabolic and Endocrine Abnormalities Linked to Sleep Difficulties in Schizophrenia? A Hypothesis Driven Review
}

\author{
Rébecca Robillard', ${ }^{1,2}$ Naomi L. Rogers ${ }^{2,3}$, Bradley G. Whitwell ${ }^{4}$, Tim Lambert ${ }^{3,4}$ \\ ${ }^{1}$ Psychology Department, Université de Montréal, Montréal, Québec, Canada, ${ }^{2}$ Chronobiology and Sleep, Institute for Health and Social \\ Science Research, Central Queensland University, Mackay, ${ }^{3}$ Concord Centre for Cardiometabolic Health in Psychosis, Concord Centre \\ for Mental Health, Concord, ${ }^{4}$ Schizophrenia Treatments and Outcomes Group, Brain and Mind Research Institute, University of Sydney, \\ Sydney, Australia
}

\begin{abstract}
Schizophrenia is a psychiatric disorder that includes symptoms such as hallucinations, disordered thoughts, disorganized or catatonic behaviour, cognitive dysfunction and sleep-wake disturbance. In addition to these symptoms, cardiometabolic dysfunction is common in patients with schizophrenia. While previously it has been thought that cardiometabolic symptoms in patients with schizophrenia were associated with medications used to manage this disorder, more recently it has been demonstrated that these symptoms are present in drug naive and unmedicated patients. Sleep-wake disturbance, resulting in chronic sleep loss has also been demonstrated to induce changes in cardiometabolic function. Chronic sleep loss has been associated with an increased risk for weight gain, obesity and cardiac and metabolic disorders, independent of other potentially contributing factors, such as smoking and body mass index. We hypothesise that the sleep-wake disturbance comorbid with schizophrenia may play a significant role in the high prevalence of cardiometabolic dysfunction observed in this patient population. Here we present a critical review of the evidence that supports this hypothesis.
\end{abstract}

KEY WORDS: Schizophrenia; Cardiometabolic risk; Causative links; Clock genes.

\section{INTRODUCTION}

Schizophrenia affects $0.5-1 \%$ of the population, a prevalence that is consistent across the world population. ${ }^{1,2)}$ This chronic psychiatric disorder causes mental perturbations that significantly alter social and occupational functioning with important consequences on the course and quality of life.

The main features of schizophrenia include delusions, hallucinations, disordered thoughts, disorganized or catatonic behaviour, blunted affect, alogia, avolition, cognitive dysfunctions and sleep difficulties. ${ }^{3-5)}$ In addition to these mental and affective symptoms, several physiological disturbances also increase the burden of schizophrenia. Changes in endocrine, metabolic and car-

Received: June 7, 2011 / Accepted: June 14, 2011

Address for correspondence: Tim Lambert, BSc, MBBS, Phd. FRANZCP

Concord Centre for Cardiometabolic Health in Psychosis, Concord Centre for Mental Health, Clinical Sciences Building C22, Concord Repatriation General Hospital, Hospital Road, Concord, New South Wales 2039, Australia

Tel: +61-2-9767-7161, Fax: +61-2-9767-7107

E-mail: tim.lambert@sydney.edu.au diovascular functions, with associated disorders affecting weight, glucose regulation, lipid metabolism and blood pressure are the source of major health problems commonly affecting people with schizophrenia. The mechanisms underlying these cardiometabolic changes are not yet fully understood.

In healthy individuals, alterations in the metabolic, cardiac and endocrine systems have been associated with chronically shortened sleep duration and circadian disruption. ${ }^{3-6)}$ To our knowledge, no study has directly addressed the possible relation between cardiometabolic dysfunctions and sleep/wake abnormalities in the schizophrenia population. Since circadian and sleep disturbances are often comorbid with schizophrenia, it could be hypothesised that sleep/circadian factors may play a role in the high rates of co-occurrence of cardiovascular and metabolism abnormalities in patients with schizophrenia.

This non-systematic review presents evidence supporting this hypothesis. The characteristics of sleep and circadian rhythms in schizophrenia will be briefly summarized before the cardiovascular, metabolic and endocrine profiles typical of this population will be exposed. Evidence on the implications of sleep in cardiometabolic, endocrine 
and metabolic functions obtained from studies in the general population will then be discussed. This evidence will lay the rationale supporting the possible role of sleep as a modulating factor in the association between cardiometabolic abnormalities and schizophrenia. The implications of common genes linked with schizophrenia, sleep patterns and cardiometabolic functions will be discussed.

\section{SLEEP AND CIRCADIAN DISTURBANCES IN SCHIZOPHRENIA}

Up to $55 \%$ of medicated patients with schizophrenia report sleep problems. ${ }^{7,8)}$ While sleep-wake abnormalities may be exacerbated by antipsychotics, especially first generation antipsychotics, evidence suggests that sleep and circadian disruptions are linked to schizophrenia independent of pharmacological treatment. ${ }^{5,7,9)}$

Sleep-wake cycle regulation operates through two interactive but distinct processes. ${ }^{10)}$ The circadian process represents the rhythmic variation of sleep and wake propensity over 24 hours that is regulated by the body clock. The homeostatic process represents the accumulation of sleep pressure (relating to the notion of sleep 'debt') with increasing time awake and its dissipation during sleep. ${ }^{11)}$ A precise interaction between the circadian and homeostatic processes defines the timing of sleep and wake periods. It also supports the maintenance of consolidated sleep episodes during the night and consolidated wake episodes during the day. ${ }^{10,12)}$ These two processes may come to play in the sleep disturbances experienced by people with schizophrenia.

\section{Homeostatic Aspects of Sleep in Schizophrenia}

Sleep studies in patients with schizophrenia highlight objective abnormalities in sleep quality and quantity that can lead to increased sleep pressure. A meta-analytic review of 20 studies with a total of 652 subjects with schizophrenia concluded that, compared to healthy controls, patients with schizophrenia take longer to fall asleep and have shorter sleep duration with lower sleep efficiency (i.e., proportion of the time in bed that is spent sleeping). ${ }^{13)}$ Additionally, there is decreased rapid eye movement (REM) sleep latency, ${ }^{14)}$ and reduced stage 4 of non-REM sleep. ${ }^{15)}$ Over time, these changes are likely to lead to a progressive accumulation of sleep debt, pressuring the homeostatic sleep system.

Because they tend to intensify before psychotic episodes, sleep disturbances are thought to be precursor symptoms of decompensation in patients with schizo- phrenia. ${ }^{16-21)}$ Accordingly, the sleep literature provides examples depicting how sustained increases in homeostatic pressure caused by multiple sleepless days with psychostimulant intake can induce psychotic symptoms such as depersonalization, reduced connection with reality, visual hallucinations and persecutory ideation, even in non-clinical populations. ${ }^{20,22-24)}$ Such findings suggest that sleep disturbances may play a role in the pathogenesis of symptoms associated with schizophrenia.

\section{Circadian Aspects of Sleep in Schizophrenia}

Circadian rhythms refer to 24 hours endogenous biological variations originating from the body clock located in the suprachiasmatic nucleus (SCN) of the hypothalamus and from peripheral oscillators located in various organs across the body that are synchronised by the SCN. ${ }^{25)}$ $\mathrm{SCN}$ dysfunction leads to alteration in the timing and duration of sleep, often misaligning sleep episodes with socially adequate timing (i.e., delaying or advancing the internal rhythms) and/or fragmenting the sleep-wake cycle with intrusions of numerous awakenings during the night and naps during the day.

Inferences about circadian rhythms are generally made by measuring 24-hour variations of behavioural/biological functions known to follow a robust circadian rhythm. These include activity levels, core body temperature and hormonal secretion. Melatonin and cortisol are often used as endocrine markers to read endogenous circadian rhythms. Melatonin is a soporific hormone secreted by the pineal gland during the night, which shows very low levels during the day. Cortisol, a glucocorticoid catabolic hormone regulated through the hypothalamic-pituitary-adrenal (HPA) axis, is associated with vigilance and stress and reaches its higher levels during the day with lower levels during the night.

Circadian studies in the schizophrenia population have reported abnormalities in the timing of these physiological rhythms in the form of phase advances and delays. ${ }^{26-31)}$ It is not yet clear what shifts circadian rhythms in one direction or the other in patients with schizophrenia. Many factors such as the phase of illness, the presence of other comorbidities, occupational status and schedules imposed by the living environment vary substantially within the schizophrenia population and are likely to influence circadian rhythms differently from one individual to another.

More consistent findings have shown that people with schizophrenia have lower melatonin levels. ${ }^{32-35)}$ and higher cortisol levels at night. ${ }^{36)}$ Consistent with these physio- 
logical changes, schizophrenia is also associated with a global disorganisation of sleep-wake episodes, with more diurnal sleep and nocturnal wake periods. ${ }^{27)}$

It has recently been proposed that the sleep-wake disturbances in schizophrenia may reflect SCN dysfunctions. ${ }^{37,38)}$ Importantly, the nitric oxide synthase immuno-reactive neurons in the SCN have been reported to be significantly less numerous in patients with schizophrenia. ${ }^{37)}$ This physiological characteristic of patients with schizophrenia could possibly come to play in the emergence of sleep-wake regulation as nitric oxide is thought to modulate sleep. ${ }^{39,40)}$

The many negative outcomes resulting from sleep and circadian difficulties may have more disturbing effects on the life of people with schizophrenia compared to the general population. Notably, it has been proposed that sleep abnormalities in schizophrenia may impair memory consolidation processes occurring during sleep and could therefore contribute to the altered cognitive profile associated with schizophrenia. ${ }^{41)}$ Sleep loss has also been associated with poorer quality of life and reduced coping resources in people with schizophrenia. ${ }^{42-44)}$ Globally, poor sleep is likely to further impair the already fragile social and occupational functioning of persons experiencing schizophrenia. ${ }^{45)}$ Social functioning may also be secondarily impaired due to the schizophrenia patient having reversed sleep/wake periods along with fragmented daytime sleep. Physiologically, these phenomena might manifest behaviourally as, or at least contribute to, negative symptoms such as anergia, and apathetic social engagement. Negative symptoms have been associated with lower counts of frontal delta waves, and loss of asymmetry in studies of all night sleeping, suggesting that there may be also physiological impairments at work too. ${ }^{46)}$

\section{CARDIOMETABOLIC AND ENDOCRINE ABNORMALITIES ASSOCIATED WITH SCHIZOPHRENIA}

Sudden cardiac deaths are three times more frequent in patients with schizophrenia than in the general population. ${ }^{47,48)}$ Moreover, the prevalence of natural deaths related to cardiovascular diseases in the schizophrenia population is estimated to range between 40 to $45 \%$. ${ }^{49)}$ However, it is premature death from cardiovascular disease that is alarming, with persons with schizophrenia having $\geq 20 \%$ shorter life spans with up to 25 years of life lost. ${ }^{50,51)}$ While patient care in schizophrenia often primarily addresses mental disturbances, these statistics high- light the importance of monitoring and treating cardiovascular and metabolic functions in this population, especially when one considers that the gap in the differential rates of standardised mortality between the general population and those with schizophrenia is widening. ${ }^{52)}$ Understanding of the phenomenon of cardiometabolic disorders in the specific context of schizophrenia is necessary to develop adapted therapeutic interventions for these patients.

While antipsychotic medication is often linked to cardiovascular and metabolic perturbations, important cardiometabolic abnormalities have been reported in drug naïve or drug-withdrawn patients with schizophrenia. ${ }^{53)}$ Therefore, even though cardiometabolic changes are likely to be modulated to a variable degree by different antipsychotic medications, schizophrenia per se is thought to be associated with cardiovascular and metabolic abnormalities independently of the concomitant effect of pharmacological agents. ${ }^{53)}$

\section{Cardiovascular Function}

Despite the wide promotion of good life habits and cardiovascular health, rates of cardiovascular abnormalities remain especially high in people with schizophrenia, who experience multiple barriers to receiving adequate physical health care. ${ }^{53)}$

Notably, Bär et $a l .{ }^{54)}$ found that mean systolic and diastolic blood pressure were significantly higher in adults with schizophrenia $(135 \mathrm{mmHg} / 84 \mathrm{mmHg}$ ) compared to healthy control subjects $(120 \mathrm{mmHg} / 74 \mathrm{mmHg})$. This difference raises the average blood pressure values close to the clinical threshold for hypertension, in the hazardous range of pre-hypertension (120-139 $\mathrm{mmHg} / 80-89 \mathrm{mmHg}$; American Heart Association, 2010). Not surprisingly, comorbidity studies estimate that the prevalence of hypertension in the schizophrenia population ranges between $27 \%$ and $45 \% .^{55-57)}$ This high prevalence bears considerable clinical significance, since high blood pressure is a risk factor for the development of many life-threatening conditions such as cardiovascular diseases, strokes and renal failure. Aside from these physical health concerns, hypertension has also been linked with decreased cognitive skills, ${ }^{58)}$ therefore further altering a dimension of life already vulnerable in schizophrenia.

While comparing the baroreflex sensitivity of patients with schizophrenia with healthy controls, Bär et al. ${ }^{54)}$ found significant alterations in the coordination of blood pressure with heart rate. These authors suggested that the decreased parasympathetic activity in schizophrenia con- 
stituted a lower counterweight to sympathetic stimulation. Moreover, compared to healthy controls, the heart rate of people with schizophrenia is more than $25 \%$ faster and shows lower variability, suggesting altered cardiac autonomic function. ${ }^{54,59)}$ Importantly, reduced baroreflex sensitivity and heart rate have been associated with increased risk of vascular events and mortality. ${ }^{60,61)}$

\section{Smoking and Lifestyle}

A recent study revealed that the prevalence of smoking in the schizophrenia population is almost two times more frequent than in the general population. These smokers with schizophrenia have been reported to have unhealthy life habits (e.g., poor diet, high intake of alcohol and caffeine, sedentary lifestyle) and to be at increased long term risk of cerebrovascular events. ${ }^{62)}$ Hence, while the full aetiology of cardiovascular abnormalities in schizophrenia remains multi-factorial, modifiable life habits are likely to potentiate them.

\section{Body Weight}

Overweight and obesity are estimated to be 1.5 to 2 times more frequent in patients with schizophrenia than in the general population. ${ }^{50,63-66)}$ Accordingly, body mass index, waist-hip ratio and waist circumference have all been shown to be significantly higher in people with schizophrenia. ${ }^{36,56,67)}$ Importantly, the fat distribution characteristic of schizophrenia differs to that of the general population. While total body fat, as measured by computed tomography scan, and subcutaneous fat are similar in schizophrenia and controls, people with schizophrenia have three times as much intra-abdominal (or central) fat. $^{36,68)}$ This specific fat distribution is highly associated with cardiovascular disturbances, hypertension, type 2 diabetes and dyslipidaemia. ${ }^{69,70)}$ Central adiposity is thought to contribute to the insulin resistance syndrome and in conjunction with its enhanced inflammatory status, in turn enhances cardiovascular risk. ${ }^{71)}$

Aside from its damaging physiological consequences, decreased physical fitness resulting from weight gain may confer an aversive aspect to physical activity and further contribute to sedentary lifestyle in schizophrenia. Alteration of body image following weight gain is thought to be a potential factor for low self-esteem and further social marginalisation in people with mental illness. ${ }^{72)}$

Chronic antipsychotic medication, especially atypical antipsychotics, has been shown to increase weight in up to $80 \%$ of patients with schizophrenia ${ }^{73,74)}$ and to have a prominent effect on abdominal fat. ${ }^{75-77)}$ For those on anti- psychotics, central H1, alpha-1-adrenergic, and 5-HT2C antagonism is highly predictive of poor hypothalamic energy balance control with subsequent weight increase. ${ }^{78)}$

Some authors have proposed that the consequences of weight gain can be distressing enough to threaten medication adherence. ${ }^{72,79)}$ Inactivity, apathy, lower socioeconomic status and bad diet have also been suggested to play a role in the aetiology of weight problems in schizophrenia. ${ }^{80)}$ Importantly, epidemiological studies have reported that patients with schizophrenia have significantly higher weight levels even when compared to lifestyle-matched controls. ${ }^{68)}$ This suggests that, while possibly intensified by external factors such as medication, socio-economic variables, eating habits, or exercise levels, and weight gain in schizophrenia operates through endogenous mechanisms. Notably, the higher caloric intake associated with schizophrenia is thought to result in part from increased appetite and decreased satiation, ${ }^{81,82)}$ which could in turn be explained by endocrine and metabolic changes.

\section{Eating Habits and Endocrine Abnormalities}

Schizophrenia has been associated with altered self-control and cognitive distortions regarding one's relation to food, such as rigid weight regulation and fear of weight gain. ${ }^{80)}$ This combination is likely to generate maladaptive eating behaviour. In fact, food intake in schizophrenia has been paralleled with several types of eating behaviour disturbances such as pica, gorging, anhedonia, and paranoia-induced starvation. ${ }^{83)}$ Moreover, the diet of patients with schizophrenia has been observed to includes increased levels of saturated fat and food with high glycaemic index. Conversely, their diet tends to be low in fibre, fruits and vegetables. ${ }^{84-87)}$ While socioeconomic and cognitive variables may contribute to this eating profile, important perturbations of hormones implicated in the regulation of appetite, weight and metabolism may also come to play as primary drivers of poor diet choices.

Ghrelin is a hunger stimulating hormone released mainly by the stomach that is associated with increased body fat ${ }^{88)}$ and is reduced by glucose and insulin. ${ }^{89)}$ Medicated patients with schizophrenia have higher ghrelin levels than healthy controls. ${ }^{67,90)}$ This endocrine imbalance is thought to contribute to the increased food-intake characteristic of schizophrenia. ${ }^{67)}$

Leptin, a hormone derived from the cells composing adipose tissues, signals satiety by sending information about ongoing energy reserves to the hypothalamus. These signals lead to a decrease in appetite. Because leptin 
levels are correlated with fat mass, some authors have proposed that obesity may be linked with a decreased reaction to leptin signals. ${ }^{91)}$ Some studies have found higher leptin levels in medicated schizophrenia patients compared to healthy controls. ${ }^{90,92)}$ However, when body mass index is controlled, patients with schizophrenia are no different from groups of healthy subjects, suggesting that the high leptin levels associated with schizophrenia may be mediated by overweight. ${ }^{92-95)}$

Cortisol is implicated in glucose homeostasis, suppresses insulin and is thought to promote obesity. Patients with schizophrenia have been reported to have higher cortisol levels than healthy controls, ${ }^{96-100)}$ possibly because of alterations in the suppression mechanisms regulating this hormone. ${ }^{101-103)}$ Cortisol receptors are especially dense in visceral fat stores and potentiate the activity of lipoprotein lipase, an enzyme implicated in fat deposition that is also highly concentrated in intra-abdominal fat stores. ${ }^{104)}$ Hence, it has been proposed that hypercortisolaemia associated with schizophrenia may increase lipoprotein lipase's central fat deposition, which is in turn associated with several cardiovascular and metabolic abnormalities. $^{36,67)}$

Cortisol has an important modulatory influence on cardiovascular and metabolic activity, notably to restore physiological homeostasis after stress. Hence, abnormalities affecting HPA axis functions can interact with cardiovascular and metabolic disturbances. Notably, high levels of anxiety have been shown to be significantly correlated with elevated diastolic blood pressure and heart rate in patients with schizophrenia. ${ }^{105)}$ Furthermore, it has recently been suggested that higher levels of stress in people suffering from schizophrenia and the subsequent frequent activation of the HPA axis could trigger symptoms associated with the metabolic syndrome. ${ }^{106,107)}$

Importantly, alterations in leptin, ghrelin and cortisol have all been associated with cardiovascular and metabolic disturbances. ${ }^{108-110)}$ Therefore, their disturbed dynamics could possibly be implicated in the high occurrence of weight gain and other cardiometabolic abnormalities in schizophrenia.

\section{Metabolic Perturbations}

The rate of metabolic disorders is markedly high in the schizophrenia population. ${ }^{111-113)}$ Notably, epidemiological studies estimate that type 2 diabetes is 2 to 3 times higher in people with schizophrenia compared to the general population. ${ }^{114)}$ Similarly, metabolic syndrome, characterised by multiple metabolic risk factors such as over- weight, elevated triglycerides, lowered high-density lipoprotein cholesterol, impaired fasting glucose levels and hypertension, is almost 2 times more prevalent in patients with schizophrenia. ${ }^{50)}$

Compared to healthy controls, patients with schizophrenia show higher glucose and insulin plasma fasting levels as well as a higher increases following glucose intake. ${ }^{98,115)}$ Schizophrenia has also been associated with hepatic insulin resistance, a condition often leading to type 2 diabetes $^{98,116,117)}$ that is also thought to mediate the association between intra-abdominal fat and cardiovascular problems. ${ }^{118)}$ Since cortisol is known to lower insulin inhibition of hepatic glucose, ${ }^{119)}$ hypercortisolaemia has been proposed to be implicated in the pathogenesis of diabetes in schizophrenia. ${ }^{106,107,120)}$

In summary, many endogenous physiological abnormalities observed in schizophrenia are likely to affect cardiovascular, endocrine and metabolic functions. Higher blood pressure, reduced baroreflex sensitivity and slower heart rate put patients with schizophrenia at higher risk of cardiovascular events. Higher levels of ghrelin and cortisol, two hormones that respectively promote food intake and central fat deposition, may contribute to endogenous weight gain mechanisms. Furthermore, interactions between these cardiovascular and weight problems are catalysed by high rates of diabetes related to insulin and glucose dysregulation. Because these factors are not easily modifiable by life habits changes, in the context of schizophrenia, they add to the obstacles complicating weight management.

\section{CARDIOMETABOLIC SENSITIVITY TO VARIATIONS IN SLEEP AND THE CIRCADIAN SYSTEM}

Ongoing research constantly deepens our understanding of the various functions of sleep, including its contribution to the maintenance of physical health. Multiple studies in healthy subjects have proposed that the homeostatic and circadian processes can impact on the regulation of many cardiovascular, endocrine and metabolic parameters that have been reported to be abnormal in schizophrenia.

\section{Increased Homeostatic Sleep Pressure}

In healthy volunteers, it has been experimentally demonstrated that increased homeostatic pressure through sleep deprivation causes a raise in systolic and diastolic blood pressure. ${ }^{56,121,122)}$ Moreover, sleep deprivation has 
been shown to reduce the decrease in systolic blood pressure after an orthostatic perturbation. ${ }^{123)}$ Hence, sleep loss not only increases basal blood pressure but also induces alterations in arterial regulation, putting individuals with sleep difficulties at higher risk for vascular events.

Studies in chronic short sleepers and experimental studies using several days of sleep restriction indicate that high homeostatic pressure also alters metabolic and endocrine functions. For instance, shortened sleep increases morning glucose levels following food intake and reduces the insulin response to glucose. ${ }^{6,124,125)}$ These changes heighten the susceptibility of short sleepers to develop type 2 diabetes. Sleep restriction has also been shown to reduce leptin while increasing ghrelin levels, ${ }^{125)}$ an imbalance likely to potentiate weight gain. Accordingly, several epidemiological studies have linked sleep disturbances with being overweight. ${ }^{126)}$

\section{Circadian Rhythms Disruptions}

Aside from regulating the sleep-wake cycle, the circadian system also has a strong influence on many cardiovascular and endocrine functions.

Leptin is subjected to a clear circadian modulation, reaching its maximum level in the evening and its lowest point in the morning. Although, ghrelin fluctuations are more affected by food intake than by circadian modulation, this hormone has also been shown to increase in the evening. ${ }^{127)}$ The secretion of cortisol by the adrenal gland also follows precise variations across 24 hours. Evening cortisol levels have been shown to increase in conditions of sleep restriction in healthy humans and high corticosterone, the dominant glucocorticoid in rodents, is associated with sleep fragmentation and lower deep sleep time. ${ }^{6,128)}$ Consequently, people with sleep difficulties are more likely to have high level of cortisol, especially in the evening when it is more likely to affect sleep onset. Glucose levels also fluctuate across 24 hours, peaking during the night. Moreover, serum glucose has a higher sensitivity to glucose intake in the evening and early night than in the morning and early afternoon, ${ }^{129)}$ while the insulin increase following glucose intake shows the reverse pattern. $^{130-132)}$

The SCN synchronises the circadian rhythms of blood pressure (through the myocardium), white adipose tissues, liver, and pancreas. When measured throughout a 24-hour cycle, blood pressure reaches its higher levels during the day and its lower levels during the night. ${ }^{133)}$

Disorganization of some of those rhythms have been shown to lead to cardiovascular and metabolic disor- ders. ${ }^{134-136)}$ Moreover, using a 10-day forced desynchrony protocol, Scheer et al. ${ }^{137)}$ recently found that shifting eating and sleep-wake rhythms of healthy adults 12 hours from their usual schedule causes an increase in postprandial glucose, insulin and blood pressure, as well as a reduction in leptin.

In summary, studies in the healthy population have revealed that chronic short sleep is associated with high blood pressure, altered arterial regulation, increased postprandial glucose, decreased postprandial insulin, increased ghrelin and cortisol and reduced leptin. Importantly, some experimental studies demonstrated that sleep loss and circadian disruptions can play a causal role in those cardiometabolic and endocrine disturbances. Hence, the various physiological responses to increased homeostatic sleep pressure and deregulation of the circadian clock could contribute to the development of weight gain, cardiovascular and metabolic disorders in schizophrenia.

\section{SLEEP AND CIRCADIAN RHYTHMS AS MODULATORS OF CARDIOMETABOLIC ABNORMALITIES IN SCHIZOPHRENIA}

Because of their impacts on cardiovascular, metabolic and endocrine functions, the high prevalence of sleep and circadian disruptions in schizophrenia may play a role in the pathogenesis of cardiometabolic abnormalities. Additionally circadian dysregulation may effect inflammation, fibrinolysis, fluid balance, and vascular reactivity. ${ }^{138)}$ Metabolic disturbance may also disturb circadian rhythms in animal models.

By increasing blood pressure, ghrelin and cortisol levels, sleep loss may trigger a cascade of cardiovascular and endocrine changes increasing the risk for cardiovascular events and weight gain. Additionally, circadian misalignment observed in patients with schizophrenia may alter the circadian regulation of appetite and weight-related hormones as well as glucose tolerance and insulin dynamics.

Chronic sleep loss increases evening cortisol and high levels of cortisol are likely to reduce the ability to initiate and/or maintain consolidated sleep. Hence, bidirectional interactions between higher cortisol levels and sleep disruptions may contribute to the perpetuation of sleep and cardiometabolic disturbances in schizophrenia.

Importantly, in the general population, reversal of sleep loss and circadian disruption minimises/ameliorates negative metabolic and cardiovascular effects. Therefore, if cardiometabolic problems in schizophrenia are linked to 
sleep/wake difficulties, sleep could be an efficient intervention target.

\section{GENETIC EVIDENCE}

The pathogenesis of schizophrenia is thought to result from the interaction between genetic and environmental factors. ${ }^{139)}$ For instance, the risk associated with genetic predisposition thought to be is further increased by exposure to prenatal infection, ${ }^{140)}$ depression of the mother during pregnancy, ${ }^{141)}$ birth in an urbanised milieu ${ }^{142)}$ and cannabis use, among others. ${ }^{143)}$

While studies assessing the contribution of specific genes and genome-wide studies have not yet reach a consensus about the genetic profile of schizophrenia, recent research has highlighted associations with genes implicated in circadian rhythms and sleep homeostasis. Notably, these studies suggested that the schizophrenia phenotype was linked with some of the core molecular clock components, such as CLOCK, ARNTL, TIMELESS, NPAS2, PER1, PER2, PER3 and ROR $\beta^{144-146)}$ (See Fig. 1 in Maury et al. ${ }^{138)}$ ).

Importantly, some of those circadian genes have also been associated with cardiovascular dysfunction. ${ }^{147)}$ and the metabolic syndrome. ${ }^{138)}$ Notably, CLOCK has been linked with lipid and glucose metabolism, platelet rhythmic activity and response of cardiomyocytes to fatty acids. ${ }^{148-150)}$ PER2 has been associated with variations in cholesterol and with the aortic endothelial function, while PER3 is linked with sympathovagal balance. ${ }^{151,152)}$ Moreover, an animal study has shown that mutation of the CLOCK gene leads to hyperphagia, obesity and metabolic syndrome characterised by hyperleptinemia, hyperlipidaemia, hepatic steatosis, hyperglycaemia, and hypoinsulinaemia. ${ }^{153)}$

These overlaps between the clock genes associated with schizophrenia and cardiovascular/metabolic factors support the hypothesis that common mechanisms may be implicated in the pathogenesis of sleep/circadian disorders and cardiometabolic disturbances in schizophrenia.

\section{CONCLUSION}

Cardiometabolic disorders, such as hypertension, type 2 diabetes, obesity and the metabolic syndrome pose a serious threat to the physical health of people with schizophrenia. Many cardiometabolic and endocrine functions are modulated by sleep and circadian factors in the general population. This hypothesis driven review proposed that the high prevalence of sleep and circadian disturbances in people with schizophrenia might impact on their cardiovascular and metabolic health.

Management of cardiometabolic disturbances in schizophrenia should include support for a healthier lifestyle and diet, appropriate psychosocial interventions, close medical monitoring with proper pharmacological treatment and careful selection of antipsychotic medication in relation to each patient's cardiometabolic risk factors. Because treatment of sleep and circadian disorders has been shown to have positive outcomes on cardiometabolic functions in the general population, future empirical studies should assess the association between sleep and cardiometabolic disturbances in patients with schizophrenia. If such an association is confirmed, it would be important to integrate the management of sleep and circadian difficulties as an additional intervention target for cardiovascular and metabolic disorders in schizophrenia.

Simple non-pharmacological interventions have proven useful to address sleep and circadian disturbances in the general population. Notably, restoration of healthy sleep habits can be achieved through behavioural and cognitive interventions, and luminotherapy can be used to realign circadian rhythms. ${ }^{154-159)}$ The efficiency of these interventions in the schizophrenia population and the subsequent effects on cardiometabolic factors should be examined to assess their possible contribution to holistic physical health intervention programs in schizophrenia. It is feasible to suggest that the measurement of basic sleep and circadian parameters should be part of any new outcomes trial for the treatment of schizophrenia, perhaps revealing an independent axis of intervention for later studies.

\section{REFERENCES}

1. Jablensky A. Schizophrenia: recent epidemiologic issues. Epidemiol Rev 1995;17:10-20.

2. Tandon R, Keshavan MS, Nasrallah HA. Schizophrenia, "just the facts" what we know in 2008. 2. Epidemiology and etiology. Schizophr Res 2008;102:1-18.

3. Bora E, Yucel M, Pantelis C. Cognitive functioning in schizophrenia, schizoaffective disorder and affective psychoses: meta-analytic study. Br J Psychiatry 2009;195:475482.

4. American Psychiatric Association. Diagnostic and statistical manual of mental disorders IV revised. Arlington: American Psychiatric Publishing; 2000.

5. Monti JM, Monti D. Sleep disturbance in schizophrenia. Int Rev Psychiatry 2005;17:247-253.

6. Spiegel K, Leproult R, Van Cauter E. Impact of sleep debt on metabolic and endocrine function. Lancet 1999;354: 1435-1439. 
7. Haffmans PM, Hoencamp E, Knegtering HJ, van Heycop ten Ham BF. Sleep disturbance in schizophrenia. Br J Psychiatry 1994;165:697-698.

8. Royuela A, Macias JA, Gil-Verona JA, Pastor JF, Maniega MA, Alonso J, et al. Sleep in schizophrenia: a preliminary study using the Pittsburgh Sleep Quality Index. Neurobiol Sleep-Wakefulness Cycle 2002;2:37-39.

9. Smith M, Hopkins D, Peveler RC, Holt RI, Woodward M, Ismail K. First- v. second-generation antipsychotics and risk for diabetes in schizophrenia: systematic review and meta-analysis. Br J Psychiatry 2008;192:406-411.

10. Borbély AA. A two process model of sleep regulation. Hum Neurobiol 1982;1:195-204.

11. Achermann P, Dijk DJ, Brunner DP, Borbély AA. A model of human sleep homeostasis based on EEG slow-wave activity: quantitative comparison of data and simulations. Brain Res Bull 1993;31:97-113.

12. Akerstedt T, Folkard S. The three-process model of alertness and its extension to performance, sleep latency, and sleep length. Chronobiol Int 1997;14:115-123.

13. Chouinard S, Poulin J, Stip E, Godbout R. Sleep in untreated patients with schizophrenia: a meta-analysis. Schizophr Bull 2004;30:957-967.

14. Zarcone VP Jr, Benson KL, Berger PA. Abnormal rapid eye movement latencies in schizophrenia. Arch Gen Psychiatry 1987;44:45-48.

15. Feinberg I, Braun M, Koresko RL, Gottlieb F. Stage 4 sleep in schizophrenia. Arch Gen Psychiatry 1969;21:262266.

16. Benson KL. Sleep in schizophrenia: impairments, correlates, and treatment. Psychiatr Clin North Am 2006;29: 1033-1045.

17. Birchwood M, Smith J, Macmillan F, Hogg B, Prasad R, Harvey $\mathrm{C}$, et al. Predicting relapse in schizophrenia: the development and implementation of an early signs monitoring system using patients and families as observers, a preliminary investigation. Psychol Med 1989;19:649-656.

18. Chemerinski E, Ho BC, Flaum M, Arndt S, Fleming F, Andreasen NC. Insomnia as a predictor for symptom worsening following antipsychotic withdrawal in schizophrenia. Compr Psychiatry 2002;43:393-396.

19. Godbout R. Sleep disturbance in schizophrenia. In: Monti $J M$, Pandi-Perumal SR, eds. Clinical Pharmacology of Sleep. Basel: Birkhäuser; 2006:125-131.

20. West LJ, Janszen HH, Lester BK, Lester BK, Cornelisoon FS Jr. The psychosis of sleep deprivation. Ann N Y Acad Sci 1962;96:66-70.

21. Zarcone VP, Benson KL. BPRS symptom factors and sleep variables in schizophrenia. Psychiatry Res 1997;66:111120.

22. Devillières P, Opitz M, Clervoy P, Stephany J. Delusion and sleep deprivation. Encephale 1996;22:229-231.

23. Freeman D, Pugh K, Vorontsova N, Southgate L. Insomnia and paranoia. Schizophr Res 2009;108:280-284.

24. Luby ED, Frohman CE, Grisell JL, Lenzo JE, Gottlieb JS Sleep deprivation: effects on behavior, thinking, motor performance, and biological energy transfer systems. Psychosom Med 1960;22:182-192.

25. Czeisler CA, Buxton OM, Khalsa SBS. The human circadian timing system and sleep-wake regulation. In: Kryger MH, Roth T, Dement WC, eds. Principles and Practices in Sleep Medicine. 4th ed. Philadelphia: Elsevier/Saunders; 2005. p.375-394.

26. Hofstetter JR, Mayeda AR, Happel CG, Lysaker PH. Sleep and daily activity preferences in schizophrenia: associa- tions with neurocognition and symptoms. $J$ Nerv Ment Dis 2003;191:408-410.

27. Morgan R, Cheadle AJ. Circadian body temperature in chronic schizophrenia. Br J Psychiatry 1976;129:350-354.

28. Van Cauter E, Linkowski P, Kerkhofs M, Hubain P, L'Hermite-Balériaux M, Leclercq $\mathrm{R}$, et al. Circadian and sleep-related endocrine rhythms in schizophrenia. Arch Gen Psychiatry 1991;48:348-356.

29. Wirz-Justice A, Cajochen C, Nussbaum P. A schizophrenic patient with an arrhythmic circadian rest-activity cycle. Psychiatry Res 1997;73:83-90.

30. Wirz-Justice A, Haug HJ, Cajochen C. Disturbed circadian rest-activity cycles in schizophrenia patients: an effect of drugs? Schizophr Bull 2001;27:497-502.

31. Wulff K, Joyce E, Middleton B, Dijk DJ, Foster RG. The suitability of actigraphy, diary data, and urinary melatonin profiles for quantitative assessment of sleep disturbances in schizophrenia: a case report. Chronobiol Int 2006;23:485495.

32. Fanget F, Claustrat B, Dalery J, Brun J, Terra JL, Marie-Cardine $\mathrm{M}$, et al. Melatonin and schizophrenia. Encephale 1989;15:505-510.

33. Ferrier IN, Arendt J, Johnstone EC, Crow TJ. Reduced nocturnal melatonin secretion in chronic schizophrenia: relationship to body weight. Clin Endocrinol (Oxf) 1982; 17:181-187.

34. Rao ML, Gross G, Strebel B, Bräunig P, Huber G, Klosterkötter J. Serum amino acids, central monoamines, and hormones in drug-naive, drug-free, and neuroleptictreated schizophrenic patients and healthy subjects. Psychiatry Res 1990;34:243-257.

35. Robinson S, Rosca P, Durst R, Shai U, Ghinea C, Schmidt $\mathrm{U}$, et al. Serum melatonin levels in schizophrenic and schizoaffective hospitalized patients. Acta Psychiatr Scand 1991;84:221-224.

36. Thakore JH, Mann JN, Vlahos I, Martin A, Reznek R. Increased visceral fat distribution in drug-naive and drugfree patients with schizophrenia. Int $J$ Obes Relat Metab Disord 2002;26:137-141.

37. Bernstein HG, Heinemann A, Krell D, Dobrowolny H, Bielau $\mathrm{H}$, Keilhoff $\mathrm{G}$, et al. Hypothalamic nitric oxide synthase in affective disorder: focus on the suprachiasmatic nucleus. Cell Mol Biol (Noisy-le-grand) 2005;51:279-284.

38. Trbovic SM. Schizophrenia as a possible dysfunction of the suprachiasmatic nucleus. Med Hypotheses 2010;74:127131.

39. Chen L, Majde JA, Krueger JM. Spontaneous sleep in mice with targeted disruptions of neuronal or inducible nitric oxide synthase genes. Brain Res 2003;973:214-222.

40. Kalinchuk AV, Stenberg D, Rosenberg PA, PorkkaHeiskanen T. Inducible and neuronal nitric oxide synthases (NOS) have complementary roles in recovery sleep induction. Eur J Neurosci 2006;24:1443-1456.

41. Göder R, Boigs M, Braun S, Friege L, Fritzer G, Aldenhoff $\mathrm{JB}$, et al. Impairment of visuospatial memory is associated with decreased slow wave sleep in schizophrenia. J Psychiatr Res 2004;38:591-599.

42. Hofstetter JR, Lysaker PH, Mayeda AR. Quality of sleep in patients with schizophrenia is associated with quality of life and coping. BMC Psychiatry 2005;5:13.

43. Martin J, Jeste DV, Caliguiri MP, Patterson T, Heaton R, Ancoli-Israel S. Actigraphic estimates of circadian rhythms and sleep/wake in older schizophrenia patients. Schizophr Res 2001;47:77-86.

44. Ritsner M, Kurs R, Ponizovsky A, Hadjez J. Perceived 
quality of life in schizophrenia: relationships to sleep quality. Qual Life Res 2004;13:783-791.

45. Lu BS, Zee PC. Circadian rhythm sleep disorders. Chest 2006;130:1915-1923.

46. Sekimoto M, Kato M, Watanabe T, Kajimura N, Takahashi $\mathrm{K}$. Reduced frontal asymmetry of delta waves during all-night sleep in schizophrenia. Schizophr Bull 2007;33: 1307-1311.

47. Appleby L, Thomas S, Ferrier N, Lewis G, Shaw J, Amos T. Sudden unexplained death in psychiatric in-patients. $\mathrm{Br}$ J Psychiatry 2000;176:405-406.

48. Ruschena D, Mullen PE, Burgess P, Cordner SM, BarryWalsh J, Drummer $\mathrm{OH}$, et al. Sudden death in psychiatric patients. Br J Psychiatry 1998;172:331-336.

49. Heilä H, Haukka J, Suvisaari J, Lönnqvist J. Mortality among patients with schizophrenia and reduced psychiatric hospital care. Psychol Med 2005;35:725-732.

50. Hennekens CH, Hennekens AR, Hollar D, Casey DE. Schizophrenia and increased risks of cardiovascular disease. Am Heart J 2005;150:1115-1121.

51. Hennekens $\mathrm{CH}$. Increasing global burden of cardiovascular disease in general populations and patients with schizophrenia. J Clin Psychiatry 2007;68 Suppl 4:4-7.

52. Saha S, Chant D, McGrath J. A systematic review of mortality in schizophrenia: is the differential mortality gap worsening over time? Arch Gen Psychiatry 2007;64:11231131.

53. Newcomer JW. Antipsychotic medications: metabolic and cardiovascular risk. J Clin Psychiatry 2007;68(Suppl 4):813.

54. Bär KJ, Letzsch A, Jochum T, Wagner G, Greiner W, Sauer H. Loss of efferent vagal activity in acute schizophrenia. J Psychiatr Res 2005;39:519-527.

55. Goff DC, Sullivan LM, McEvoy JP, Meyer JM, Nasrallah HA, Daumit GL, et al. A comparison of ten-year cardiac risk estimates in schizophrenia patients from the CATIE study and matched controls. Schizophr Res 2005;80:45-53.

56. Kato M, Phillips BG, Sigurdsson G, Narkiewicz K, Pesek CA, Somers VK. Effects of sleep deprivation on neural circulatory control. Hypertension 2000;35:1173-1175.

57. Weber NS, Cowan DN, Millikan AM, Niebuhr DW. Psychiatric and general medical conditions comorbid with schizophrenia in the National Hospital Discharge Survey. Psychiatr Serv 2009;60:1059-1067.

58. Birkenhäger WH, Forette F, Seux ML, Wang JG, Staessen JA. Blood pressure, cognitive functions, and prevention of dementias in older patients with hypertension. Arch Intern Med 2001;161:152-156.

59. Jindal R, MacKenzie EM, Baker GB, Yeragani VK. Cardiac risk and schizophrenia. J Psychiatry Neurosci 2005; 30:393-395.

60. Fedorowski A, Stavenow L, Hedblad B, Berglund G, Nilsson PM, Melander O. Orthostatic hypotension predicts all-cause mortality and coronary events in middle-aged individuals (The Malmo Preventive Project). Eur Heart J 2010;31:85-91.

61. Tsuji H, Larson MG, Venditti FJ Jr, Manders ES, Evans $\mathrm{JC}$, Feldman $\mathrm{CL}$, et al. Impact of reduced heart rate variability on risk for cardiac events. The Framingham Heart Study. Circulation 1996;94:2850-2855.

62. Bobes J, Arango C, Garcia-Garcia M, Rejas J. Healthy lifestyle habits and 10-year cardiovascular risk in schizophrenia spectrum disorders: an analysis of the impact of smoking tobacco in the CLAMORS schizophrenia cohort. Schizophr Res 2010;119:101-109.
63. Birkenaes AB, Søgaard AJ, Engh JA, Jonsdottir H, Ringen PA, Vaskinn A, et al. Sociodemographic characteristics and cardiovascular risk factors in patients with severe mental disorders compared with the general population. $J$ Clin Psychiatry 2006;67:425-433.

64. Dickerson FB, Brown CH, Kreyenbuhl JA, Fang L, Goldberg RW, Wohlheiter K, et al. Obesity among individuals with serious mental illness. Acta Psychiatr Scand 2006;113:306-313.

65. Filik R, Sipos A, Kehoe PG, Burns T, Cooper SJ, Stevens $\mathrm{H}$, et al. The cardiovascular and respiratory health of people with schizophrenia. Acta Psychiatr Scand 2006;113: 298-305.

66. Susce MT, Villanueva N, Diaz FJ, de Leon J. Obesity and associated complications in patients with severe mental illnesses: a cross-sectional survey. J Clin Psychiatry 2005; 66:167-173.

67. Palik E, Birkás KD, Faludi G, Karádi I, Cseh K. Correlation of serum ghrelin levels with body mass index and carbohydrate metabolism in patients treated with atypical antipsychotics. Diabetes Res Clin Pract 2005;68 (Suppl 1):S60-S64.

68. Ryan MC, Flanagan S, Kinsella U, Keeling F, Thakore JH. The effects of atypical antipsychotics on visceral fat distribution in first episode, drug-naive patients with schizophrenia. Life Sci 2004;74:1999-2008.

69. Björntorp P. Metabolic implications of body fat distribution. Diabetes Care 1991;14:1132-1143.

70. Kissebah AH, Krakower GR. Regional adiposity and morbidity. Physiol Rev 1994;74:761-811.

71. Brunzell JD, Davidson M, Furberg CD, Goldberg RB, Howard BV, Stein JH, et al; American College of Cardiology Foundation. Lipoprotein management in patients with cardiometabolic risk: consensus statement from the American Diabetes Association and the American College of Cardiology Foundation. Diabetes Care 2008;31:811-822.

72. Stanton JM. Weight gain associated with neuroleptic medication: a review. Schizophr Bull 1995;21:463-472.

73. Baptista T. Body weight gain induced by antipsychotic drugs: mechanisms and management. Acta Psychiatr Scand 1999;100:3-16.

74. Wirshing DA, Wirshing WC, Kysar L, Berisford MA, Goldstein D, Pashdag J, et al. Novel antipsychotics: comparison of weight gain liabilities. J Clin Psychiatry 1999; 60:358-363.

75. Green AI, Patel JK, Goisman RM, Allison DB, Blackburn G. Weight gain from novel antipsychotic drugs: need for action. Gen Hosp Psychiatry 2000;22:224-235.

76. Stedman T, Welham J. The distribution of adipose tissue in female in-patients receiving psychotropic drugs. $\mathrm{Br} \mathrm{J}$ Psychiatry 1993;162:249-250.

77. Zimmermann U, Kraus T, Himmerich H, Schuld A, Pollmächer T. Epidemiology, implications and mechanisms underlying drug-induced weight gain in psychiatric patients. J Psychiatr Res 2003;37:193-220.

78. Kim SF, Huang AS, Snowman AM, Teuscher C, Snyder SH. From the Cover: Antipsychotic drug-induced weight gain mediated by histamine $H 1$ receptor-linked activation of hypothalamic AMP-kinase. Proc Natl Acad Sci U A 2007;104:3456-3459.

79. Nasrallah H. A review of the effect of atypical antipsychotics on weight. Psychoneuroendocrinology 2003;28(Suppl 1):83-96.

80. Khazaal Y, Frésard E, Zimmermann G, Trombert NM, Pomini V, Grasset F, et al. Eating and weight related 
cognitions in people with Schizophrenia : a case control study. Clin Pract Epidemiol Ment Health 2006;2:29.

81. Brömel T, Blum WF, Ziegler A, Schulz E, Bender M, Fleischhaker C, et al. Serum leptin levels increase rapidly after initiation of clozapine therapy. Mol Psychiatry 1998; 3:76-80.

82. Leadbetter R, Shutty M, Pavalonis D, Vieweg V, Higgins P, Downs M. Clozapine-induced weight gain: prevalence and clinical relevance. Am J Psychiatry 1992;149:68-72.

83. Yum SY, Caracci G, Hwang MY. Schizophrenia and eating disorders. Psychiatr Clin North Am 2009;32:809-819.

84. Brown S, Birtwistle J, Roe L, Thompson C. The unhealthy lifestyle of people with schizophrenia. Psychol Med 1999; 29:697-701.

85. McCreadie R, Macdonald E, Blacklock C, Tilak-Singh D, Wiles D, Halliday J, et al. Dietary intake of schizophrenic patients in Nithsdale, Scotland: case-control study. BMJ 1998;317:784-785.

86. McCreadie RG; Scottish Schizophrenia Lifestyle Group. Diet, smoking and cardiovascular risk in people with schizophrenia: descriptive study. Br J Psychiatry 2003;183: 534-539.

87. McCreadie RG, Kelly C, Connolly M, Williams S, Baxter $\mathrm{G}$, Lean $\mathrm{M}$, et al. Dietary improvement in people with schizophrenia: randomised controlled trial. Br J Psychiatry 2005;187:346-351.

88. Sentissi O, Epelbaum J, Olié JP, Poirier MF. Leptin and ghrelin levels in patients with schizophrenia during different antipsychotics treatment: a review. Schizophr Bull 2008;34:1189-1199.

89. Formiguera X, Cantón A. Obesity: epidemiology and clinical aspects. Best Pract Res Clin Gastroenterol 2004;18:11251146.

90. Murashita M, Inoue T, Kusumi I, Nakagawa S, Itoh K, Tanaka T, et al. Glucose and lipid metabolism of long-term risperidone monotherapy in patients with schizophrenia. Psychiatry Clin Neurosci 2007;61:54-58.

91. Friedman JM. The function of leptin in nutrition, weight, and physiology. Nutr Rev 2002;60:S1-S14.

92. Eder U, Mangweth B, Ebenbichler C, Weiss E, Hofer A, Hummer M, et al. Association of olanzapine-induced weight gain with an increase in body fat. Am J Psychiatry 2001;158:1719-1722.

93. Arranz B, Rosel P, Ramírez N, Dueñas R, Fernández P, Sanchez JM, et al. Insulin resistance and increased leptin concentrations in noncompliant schizophrenia patients but not in antipsychotic-naive first-episode schizophrenia patients. J Clin Psychiatry 2004;65:1335-1342.

94. Atmaca M, Tezcan E, Ustundag B. Plasma nitric oxide and leptin values in patients with olanzapine-induced weight gain. J Psychiatr Res 2007;41:74-79.

95. Baptista T, Lacruz A, Angeles F, Silvera R, de Mendoza $\mathrm{S}$, Mendoza MT, et al. Endocrine and metabolic abnormalities involved in obesity associated with typical antipsychotic drug administration. Pharmacopsychiatry 2001; 34:223-231.

96. Christie JE, Whalley LJ, Dick H, Fink G. 7. Corticosteroid secretion--clinical aspects. Plasma cortisol concentrations in the functional psychoses and Alzheimer type dementia: a neuroendocrine day approach in drug-free patients. $J$ Steroid Biochem 1983;19:247-250.

97. Gil-Ad I, Dickerman Z, Amdursky S, Laron Z. Diurnal rhythm of plasma beta endorphin, cortisol and growth hormone in schizophrenics as compared to control subjects. Psychopharmacology (Berl) 1986;88:496-499.
98. Ryan MC, Collins P, Thakore JH. Impaired fasting glucose tolerance in first-episode, drug-naive patients with schizophrenia. Am J Psychiatry 2003;160:284-289.

99. Walder DJ, Walker EF, Lewine RJ. Cognitive functioning, cortisol release, and symptom severity in patients with schizophrenia. Biol Psychiatry 2000;48:1121-1132.

100. Whalley LJ, Christie JE, Bennie J, Dick H, Blackburn IM, Blackwood $\mathrm{D}$, et al. Selective increase in plasma luteinising hormone concentrations in drug free young men with mania. Br Med J (Clin Res Ed) 1985;290:99-102.

101. Lammers CH, Garcia-Borreguero D, Schmider J, Gotthardt $\mathrm{U}$, Dettling $\mathrm{M}$, Holsboer $\mathrm{F}$, et al. Combined dexamethasone/corticotropin-releasing hormone test in patients with schizophrenia and in normal controls: II. Biol Psychiatry 1995;38:803-807.

102. Mück-Seler D, Pivac N, Jakovljević M, Brzović Z. Platelet serotonin, plasma cortisol, and dexamethasone suppression test in schizophrenic patients. Biol Psychiatry 1999;45: 1433-1439.

103. Pivac N, Mück-Seler D, Jakovljević M. Platelet 5-HT levels and hypothalamic-pituitary-adrenal axis activity in schizophrenic patients with positive and negative symptoms. Neuropsychobiology 1997;36:19-21.

104. Ottosson M, Vikman-Adolfsson K, Enerbäck S, Olivecrona G, Björntorp P. The effects of cortisol on the regulation of lipoprotein lipase activity in human adipose tissue. J Clin Endocrinol Metab 1994;79:820-825.

105. Townsend MH, Baier MB, Becker JE, Ritchie MA. Blood pressure, heart rate, and anxiety in schizophrenia. Psychiatry Res 2007;151:155-157.

106. Afzal N, Thakore J. Stress axis dysfunction: A common finding in schizophrenia and the metabolic syndrome? In: Thakore J, Leonard BE, editors. Metabolic Effects of Psychotropic Drugs. Mod Trends Pharmacopsychiatry. Basel: Karger; 2009. p.82-89.

107. Bradley AJ, Dinan TG. A systematic review of hypothalamic-pituitary-adrenal axis function in schizophrenia: implications for mortality. J Psychopharmacol 2010;24(4 Suppl):91-118.

108. Pasquali R, Vicennati V, Cacciari M, Pagotto U. The hypothalamic-pituitary-adrenal axis activity in obesity and the metabolic syndrome. Ann N Y Acad Sci 2006;1083: 111-128.

109. Patel SB, Reams GP, Spear RM, Freeman RH, Villarreal D. Leptin: linking obesity, the metabolic syndrome, and cardiovascular disease. Curr Hypertens Rep 2008;10:131137.

110. Ukkola O, Pöykkö SM, Antero Kesäniemi Y. Low plasma ghrelin concentration is an indicator of the metabolic syndrome. Ann Med 2006;38:274-279.

111. Bushe C, Holt R. Prevalence of diabetes and impaired glucose tolerance in patients with schizophrenia. $\mathrm{Br} J$ Psychiatry Suppl 2004;47:S67-S71.

112. Cohen D, Stolk RP, Grobbee DE, Gispen-de Wied CC. Hyperglycemia and diabetes in patients with schizophrenia or schizoaffective disorders. Diabetes Care 2006;29:786791.

113. McEvoy JP, Meyer JM, Goff DC, Nasrallah HA, Davis SM, Sullivan L, et al. Prevalence of the metabolic syndrome in patients with schizophrenia: baseline results from the Clinical Antipsychotic Trials of Intervention Effectiveness (CATIE) schizophrenia trial and comparison with national estimates from NHANES III. Schizophr Res 2005;80:19-32.

114. Holt RI, Bushe C, Citrome L. Diabetes and schizophrenia 
2005: are we any closer to understanding the link? J Psychopharmacol 2005;19(6 Suppl):56-65.

115. Yasui-Furukori N, Sato Y, Furukori H, Saito M, Nakagami T, Kaneko S. Glucose metabolism in Japanese schizophrenia patients treated with risperidone or olanzapine. $J$ Clin Psychiatry 2009;70:95-100.

116. Cohn TA, Remington G, Zipursky RB, Azad A, Connolly $\mathrm{P}$, Wolever TM. Insulin resistance and adiponectin levels in drug-free patients with schizophrenia: A preliminary report. Can J Psychiatry 2006;51:382-386.

117. van Nimwegen LJ, Storosum JG, Blumer RM, Allick G, Venema HW, de Haan L, et al. Hepatic insulin resistance in antipsychotic naive schizophrenic patients: stable isotope studies of glucose metabolism. J Clin Endocrinol Metab 2008;93:572-577.

118. Schmidt MI, Watson RL, Duncan BB, Metcalf P, Brancati $\mathrm{FL}$, Sharrett AR, et al. Clustering of dyslipidemia, hyperuricemia, diabetes, and hypertension and its association with fasting insulin and central and overall obesity in a general population. Atherosclerosis Risk in Communities Study Investigators. Metabolism 1996;45:699-706.

119. Meyer G, Badenhoop K. Glucocorticoid-induced insulin resistance and diabetes mellitus. Receptor-, postreceptor mechanisms, local cortisol action, and new aspects of antidiabetic therapy. Med Klin (Munich) 2003;98:266-270.

120. Dinan TG. Stress and the genesis of diabetes mellitus in schizophrenia. Br J Psychiatry Suppl 2004;47:S72-S75.

121. Ogawa Y, Kanbayashi T, Saito Y, Takahashi Y, Kitajima $\mathrm{T}$, Takahashi $\mathrm{K}$, et al. Total sleep deprivation elevates blood pressure through arterial baroreflex resetting: a study with microneurographic technique. Sleep 2003;26: 986-989.

122. Tochikubo O, Ikeda A, Miyajima E, Ishii M. Effects of insufficient sleep on blood pressure monitored by a new multibiomedical recorder. Hypertension 199;27:1318-1324.

123. Robillard R, Lanfranchi PA, Prince F, Filipini D, Carrier J. Sleep deprivation increases blood pressure in healthy normotensive elderly and attenuates the blood pressure response to orthostatic challenge. Sleep 2011;34:335-339.

124. Leproult R, Copinschi G, Buxton O, Van Cauter E. Sleep loss results in an elevation of cortisol levels the next evening. Sleep 1997;20:865-870.

125. Spiegel K, Tasali E, Penev P, Van Cauter E. Brief communication: Sleep curtailment in healthy young men is associated with decreased leptin levels, elevated ghrelin levels, and increased hunger and appetite. Ann Intern Med 2004; 141:846-850.

126. Cappuccio FP, Taggart FM, Kandala NB, Currie A, Peile E, Stranges S, et al. Meta-analysis of short sleep duration and obesity in children and adults. Sleep 2008;31:619-626.

127. Yildiz BO, Suchard MA, Wong ML, McCann SM, Licinio J. Alterations in the dynamics of circulating ghrelin, adiponectin, and leptin in human obesity. Proc Natl Acad Sci U S A 2004;101:10434-10439.

128. Dugovic C, Maccari S, Weibel L, Turek FW, Van Reeth $\mathrm{O}$. High corticosterone levels in prenatally stressed rats predict persistent paradoxical sleep alterations. J Neurosci 1999; 19:8656-8664.

129. Van Cauter E, Shapiro ET, Tillil H, Polonsky KS. Circadian modulation of glucose and insulin responses to meals: relationship to cortisol rhythm. Am J Physiol 1992; 262:E467-E475.

130. Aparicio NJ, Puchulu FE, Gagliardino JJ, Ruiz M, Llorens $\mathrm{JM}$, Ruiz J, et al. Circadian variation of the blood glucose, plasma insulin and human growth hormone levels in response to an oral glucose load in normal subjects. Diabetes 1974;23:132-137.

131. Carroll KF, Nestel PJ. Diurnal variation in glucose tolerance and in insulin secretion in man. Diabetes 1973;22: 333-348.

132. Zimmet PZ, Wall JR, Rome R, Stimmler L, Jarrett RJ. Diurnal variation in glucose tolerance: associated changes in plasma insulin, growth hormone, and non-esterified fatty acids. $\mathrm{Br}$ Med $\mathrm{J}$ 1974;1:485-488.

133. Millar-Craig MW, Bishop CN, Raftery EB. Circadian variation of blood-pressure. Lancet 1978;1:795-797.

134. Di Iorio A, Marini E, Lupinetti M, Zito M, Abate G. Blood pressure rhythm and prevalence of vascular events in hypertensive subjects. Age Ageing 1999;28:23-28.

135. Hoshide S, Kario K, Hoshide Y, Umeda Y, Hashimoto T, Kunii $\mathrm{O}$, et al. Associations between nondipping of nocturnal blood pressure decrease and cardiovascular target organ damage in strictly selected community-dwelling normotensives. Am J Hypertens 2003;16:434-438.

136. Van Cauter E, Polonsky KS, Scheen AJ. Roles of circadian rhythmicity and sleep in human glucose regulation. Endocr Rev 1997; 18:716-738.

137. Scheer FA, Hilton MF, Mantzoros CS, Shea SA. Adverse metabolic and cardiovascular consequences of circadian misalignment. Proc Natl Acad Sci U S A 2009;106:44534458.

138. Maury E, Ramsey KM, Bass J. Circadian rhythms and metabolic syndrome: from experimental genetics to human disease. Circ Res 2010;106:447-462.

139. Gejman PV, Sanders AR, Duan J. The role of genetics in the etiology of schizophrenia. Psychiatr Clin North Am 2010;33:35-66.

140. Clarke MC, Tanskanen A, Huttunen M, Whittaker JC, Cannon M. Evidence for an interaction between familial liability and prenatal exposure to infection in the causation of schizophrenia. Am J Psychiatry 2009;166:1025-1030.

141. Mäki P, Riekki T, Miettunen J, Isohanni M, Jones PB, Murray GK, et al. Schizophrenia in the offspring of antenatally depressed mothers in the northern Finland 1966 birth cohort: relationship to family history of psychosis. Am J Psychiatry 2010;167:70-77.

142. van Os J, Pedersen CB, Mortensen PB. Confirmation of synergy between urbanicity and familial liability in the causation of psychosis. Am J Psychiatry 2004;161:23122314.

143. van Os J, Kenis G, Rutten BP. The environment and schizophrenia. Nature 2010;468:203-212.

144. Lamont EW, Legault-Coutu D, Cermakian N, Boivin DB. The role of circadian clock genes in mental disorders. Dialogues Clin Neurosci 2007;9:333-342.

145. Mansour HA, Talkowski ME, Wood J, Chowdari KV, McClain L, Prasad K, et al. Association study of 21 circadian genes with bipolar I disorder, schizoaffective disorder, and schizophrenia. Bipolar Disord 2009;11:701710.

146. Mansour HA, Wood J, Logue T, Chowdari KV, Dayal M, Kupfer DJ, et al. Association study of eight circadian genes with bipolar I disorder, schizoaffective disorder and schizophrenia. Genes Brain Behav 2006;5:150-157.

147. Mongrain V, Cermakian N. Clock genes in health and diseases. J Appl Biomed 2009;7:15-33.

148. Durgan DJ, Trexler NA, Egbejimi O, McElfresh TA, Suk HY, Petterson LE, et al. The circadian clock within the cardiomyocyte is essential for responsiveness of the heart to fatty acids. J Biol Chem 2006;281:24254-24269. 
149. Kennaway DJ, Owens JA, Voultsios A, Boden MJ, Varcoe TJ. Metabolic homeostasis in mice with disrupted Clock gene expression in peripheral tissues. Am J Physiol Regul Integr Comp Physiol 2007;293:R1528-R1537.

150. Ohkura N, Oishi K, Sudo T, Hayashi H, Shikata K, Ishida $\mathrm{N}$, et al. CLOCK regulates circadian platelet activity. Thromb Res 2009;123:523-527.

151. Viola F, Ellis MA, Walker WF. Time-domain optimized near-field estimator for ultrasound imaging: initial development and results. IEEE Trans Med Imaging 2008;27:99110.

152. Viswambharan H, Carvas JM, Antic V, Marecic A, Jud C, Zaugg CE, et al. Mutation of the circadian clock gene Per2 alters vascular endothelial function. Circulation 2007;115: 2188-2195.

153. Turek FW, Joshu C, Kohsaka A, Lin E, Ivanova G, McDearmon $\mathrm{E}$, et al. Obesity and metabolic syndrome in circadian Clock mutant mice. Science 2005;308:1043-1045.

154. Boivin DB, Duffy JF, Kronauer RE, Czeisler CA. Doseresponse relationships for resetting of human circadian clock by light. Nature 1996;379:540-542.

155. Edinger JD, Wohlgemuth WK, Radtke RA, Marsh GR, Quillian RE. Cognitive behavioral therapy for treatment of chronic primary insomnia: a randomized controlled trial. JAMA 2001;285:1856-1864.

156. Espie CA, Inglis SJ, Tessier S, Harvey L. The clinical effectiveness of cognitive behaviour therapy for chronic insomnia: implementation and evaluation of a sleep clinic in general medical practice. Behav Res Ther 2001;39:4560 .

157. Khalsa SB, Jewett ME, Cajochen C, Czeisler CA. A phase response curve to single bright light pulses in human subjects. J Physiol 2003;549:945-952.

158. Morin CM, Culbert JP, Schwartz SM. Nonpharmacological interventions for insomnia: a meta-analysis of treatment efficacy. Am J Psychiatry 1994;151:1172-1180.

159. Wright KP Jr, Gronfier C, Duffy JF, Czeisler CA. Intrinsic period and light intensity determine the phase relationship between melatonin and sleep in humans. J Biol Rhythms 2005;20:168-177. 